\title{
Medicina e fauna silvestre em Minas Gerais no século XVIII*
}

\author{
Minas Gerais' medicine and \\ wild fauna in the XVIII century
}

RAFAEL DE FREITAS E SOUZA

Doutorando em História Social/USP

Caixa Postal 112 - Viçosa - MG

CEP: 26570-000

rf.souza@bol.com.br

RESUMO O presente artigo delineia reflexão acerca da obra Erário Mineral de Luís Gomes Ferreira - cirurgião português que atuou em Minas Gerais durante vinte anos na primeira metade do século XVIII. A referida obra sintetiza sua preocupação em adequar os conhecimentos à nova realidade (clima, doenças e recursos disponíveis). A partir do levantamento dos animais pertencentes à "fauna silvestre mineira" empregados em seu receituário, busca-se compreender o sentido histórico do recurso a elementos da natureza na cura das enfermidades, bem como as conseqüências da ação antrópica sobre o meio ambiente ao longo do processo civilizador nesta capitania.

Palavras-chave Minas Gerais, História Ambiental, Medicina

Artigo recebido em: 10/03/2007. Aprovado em: 28/11/2007. 
ABSTRACT The present article deliniate a reflection concerning Luís Gomes Ferreira's book, Erário Mineral. Luís Gomes Ferreira was a Portuguese surgeon that worked in Minas Gerais for twenty years in the first half of the century XVIII. Referred her work it synthesizes your concern in adapting the knowledge to the new reality (climate, diseases and available resources). Starting from the rising of the animals belonging to "the wild fauna of Minas Gerais" employed in your receituário, it is looked for to understand the sense report of the resource to elements of the nature in the cure of the illnesses, as well as the consequences of the human action on the environment along the civilization process in this captaincy.

Key words Minas Gerais, Environment History, Medicine

\section{O cirurgião e a sua obra}

Luís Gomes Ferreira, cirurgião aprovado, como tantos outros reinóis, veio para o Brasil na fase do rush do ouro de Minas. Seguindo a mesma tipicidade da itinerância dos primeiros colonizadores, habitou primeiro na Bahia, onde aportou em 1707. No ano de 1711 decide se estabelecer em Sabará. Até 1932, ano de seu retorno para Portugal, residiu em Ribeirão Abaixo (distrito de São Caetano), Vila de Nossa Senhora do Carmo, arraial do Padre Faria, situado na então promissora Vila Rica. Voltou mais rico do que chegara em virtude de sua tripla atividade econômica: lavra aurífera, roça e ofício de cirurgião. ${ }^{1}$

A eterna e inglória batalha da vida contra a morte acompanhou sua trajetória ao longo dos anos que residiu nestas paragens. Sofreu em seu próprio corpo doenças que combateu em outrem (surdez, erisipela, corrupção-do-bicho, oftalmia, sarna, calo e chaga na garganta) das quais se curou experimentando em si remédios que inventou e passou adiante.

Ferreira encontrou muito mais que ouro em Minas Gerais. Deparou-se com uma realidade "aonde não chegam médicos, nem ainda cirurgiões que professam a cirurgia, por cuja causa padecem os povos grandes necessidades". ${ }^{2}$ Em outras palavras, uma região ainda inóspita, violenta, insalubre, isolada do litoral, com crescente densidade populacional, carente de médicos e cirurgiões autorizados, onde o tratamento e cura das enfermidades dependiam do conhecimento das propriedades mágico-terapêuticas dos

1 Biografia completa e detalhada de Luís Gomes Ferreira pode ser encontrada nos estudos críticos redigidos por J únia F. Furtado, Eliane S. Muzzi, Maria Odila L. Silva Dias, Maria Cristina C. Wissembach e Ronaldo S. Coelho, redigidos para a edição patrocinada pelas Fundações J oão Pinheiro e Fundação Oswaldo Cruz. Ver: FERREIRA, Luís Gomes. Erário Mineral. Organização J unia Ferreira Furtado. Belo Horizonte: Fundação J oão Pinheiro/Rio de J aneiro: Fundação Oswaldo Cruz, 2002. (Coleção Mineiriana).

2 FERREIRA, Luís Gomes. Erário Mineral, Prólogo, v.1, p.84. 
elementos extraídos da fauna, flora, minerais, do corpo humano e de alguns elementos químicos já conhecidos.

Saber que cada vez mais se amalgamava com as tradições indígena, africana, européia e árabe; popular e erudita. Ferreira é claro acerca deste trânsito entre saberes medicinais: "Este modo de cura inventaram os carijós do mato, e deles passou aos paulistas e destes a nós", ${ }^{3}$ formando o que se conceitua como "circularidade dos níveis culturais". ${ }^{4}$ Saber onde os limites entre magia, religião, sexualidade, medicina e cirurgia eram quase imperceptíveis. Tudo isso, num ambiente cultural marcado pela sincera crença na influência de poderes sobrenaturais - malignos e benignos - sobre 0 bem-estar individual e coletivo.

Para suprir esta carência de seguras e experimentadas formas de tratamento das mais diversas doenças e adversidades foi que Luís Gomes Ferreira escreveu o Erário Mineral. Sua obra obteve relativo sucesso em Minas, onde era revendida pelo livreiro J erônimo Roiz Airão. Manuel Ribeiro dos Santos - o exigente livreiro de Vila Rica, na carta de 4 de julho de 1750 endereçada a Luís Salgado dos Santos em Lisboa, assim pede: "2 tom. De Medicina Irario Mineral autor Luiz Gomes Ferr.a q'. morou nesta v.a e curou o Nevez". ${ }^{5}$ Em outra carta dirigida a Manuel Carvalho Silva, solicita "1 Tom. De Medicina Irario Mineral, autor Luiz Gomes Fer.a q'. morou nestas Minnas e curou por Sirurgia nellas". ${ }^{6}$ Em sua pesquisa, Araújo o encontrou em diversos inventários de moradores de Sabará e também no inventário do baiano Antônio da Costa em 1748.

J únia Furtado considera Ferreira o fundador de uma "Medicina tropical". ${ }^{7}$ Afirmativa válida, pois se preocupou em combater as doenças típicas dos trópicos recorrendo a elementos desta mesma região do globo, além de sistematizar este saber em sua obra, orientado pela experiência, espírito crítico e a tentativa de se afastar do curandeirismo. É certamente por estas características, que o Erário adquiriu relativa popularidade na América portuguesa setecentista.

\section{A Fauna de Minas Gerais ${ }^{8}$}

Pretende-se aqui, proceder exclusivamente ao levantamento dos animais pertencentes à 'fauna silvestre mineira' inclusos na elaboração das receitas de Luís Gomes Ferreira: aqueles que eram empregados, as partes

FERREIRA, Luís Gomes. Erário Mineral, v. 2, p.657.

MAUSS, Marcel. Sociologia e antropologia. São Paulo: Epu/Edusp, 1974.

ARAÚJ O, J osé de Souza. Perfil do leitor colonial. Salvador: UFBA/llhéus: UESC, 1999, p.125.

FERREIRA, Luís Gomes. Erário Mineral, v.1, p.127.

7 FURTADO, J únia Ferreira. Arte e segredo: o licenciado Luís Gomes Ferreira e seu caleidoscópio de imagens. In: FERREIRA, Luís Gomes. Erário Mineral, v.1, p.26.

8 Agradeço especialmente a Letícia Maria Rodrigues Gomes, bióloga e doutoranda em Ciência Florestal na UFV, pelos esclarecimentos prestados referentes a seus campos de conhecimento. 
de sua anatomia e o fim a que serviam (Q uadro 1). Deixamos de lado o largo recurso que fazia à flora, minerais, produtos químicos, elementos do corpo humano, animais já domesticados pelo homem (cães, gatos, bois, etc.) e aqueles de outras regiões (enguia de água doce e caranguejo do rio).

É preciso esclarecer que os animais referidos adiante não são endêmicos a Minas, mas eram aí também encontrados, aos quais os habitantes poderiam recorrer in loco. É a isto que estamos denominando 'fauna silvestre mineira'. Adotamos aqui o conceito de fauna silvestre na acepção de Zanzini:

A fauna silvestre compreende todas as es pécies animais que vivem no ambiente livres de quaisquer normas de domesticação. Tal definição, evidentemente, inclui todos os organismos que exercem o papel de consumidores na cadeia trófica, sejam eles vertebrados ou invertebrados, sobre os quais não incidem regras pecuárias capazes de impedir seu processo de seleção natural. ${ }^{9}$

Esta definição pode causar estranheza àqueles habituados a ver a fauna silvestre somente representada pela macrofauna. Não, para o equilíbrio de qualquer ecossistema nenhum animal, fungo ou bactéria é insignificante, todos exercem importante papel na dinâmica da vida. Daí, não excluirmos do levantamento os roedores, insetos (a mosca: importante agente decompositor e o percevejo) e anelídeos como a minhoca. ${ }^{10}$

0 encontro dos europeus com a exuberante fauna das matas e rios de Minas provocou profundo impacto em seu imaginário. ${ }^{11}$ Logo passaram a fazer parte de seus relatos, livros e dos receituários médicos. Entre aves, mamíferos e répteis, era abundante a presença da ema, jacutinga, loboguará, onça, veado, anta, cutia, catitu, capivara, tamanduá, macacos, jacaré, tartaruga, cobras diversas e uma infinidade de insetos como formigas, besouros e cupins. ${ }^{12}$

A fauna silvestre, além de importante item na alimentação dos colonos, usavam-na também como adorno (penas aplicadas em chapéus), vestuário (botas), trabalho (peles eram colocadas sob a sela dos cavalos), decoração doméstica, atributo de coragem masculina e costume courtois. Além

9 ZANZINI, Antônio Carlos da Silva. Fauna silvestre. Lavras: UFLA/FAEPE, 2000, p.1.

10 Cf. BARNES, Robert D. Zoologia dos invertebrados. Trad. J esus E. de Paula Assis et all. São Paulo: Livraria Roca, 1990.

11 Cf. HOLANDA, Sérgio Buarque de Holanda. Visão do Paraíso: os motivos edênicos no descobrimento e colonização do Brasil. 2a.ed. São Paulo: Companhia. Editora Nacional/Edusp, 1969. Sobretudo o capítulo VIII - Visão do Paraíso, onde escreve sobre as impressões que tiveram os Europeus acerca do papagaio, ave considerada paradisíaca e da denominação dada ao Brasil como Terra delli Papagá. Veja também FREYRE, Gilberto. CasaGrande e Senzala: formação da família brasileira sob o regime da economia patriarcal. 23a.ed. Rio de J aneiro: Livraria J osé Olympio, 1984. À página 25 emite opinião sobre os traficantes de papagaios. Leia ainda FURTADO, J únia Ferreira. As índias do conhecimento, ou a geografia imaginária da conquista do ouro. In: CONSENTINO, Francisco Carlos; SOUZA, Marco Antônio de. (org). 1500-2000: trajetórias. Belo Horizonte: Centro Universitário Newton Paiva, 1999, p.21-32.

12 Sobre a composição da fauna e flora de Minas Gerais leia ARAÚJ O, Marcos Antonio Reis. Conservação da biodiversidade em Minas Gerais: em busca de uma estratégia para o século XXI. Belo Horizonte: Unicentro Newton Paiva, 2000. Veja também NEIMAN, Zysman. Era verde? Ecossistemas brasileiros ameaçados. Belo Horizonte: Editora Atual, sd., 99p. 
disso, a 'fauna silvestre mineira' foi largamente empregada no receituário setecentista, tão bem sistematizado por Luís Gomes Ferreira. ${ }^{13}$

\section{A Longa Duração do Recurso à Fauna Brasileira}

Segundo Wissenbach, a busca pela descoberta de plantas ou animais do Novo Mundo que pudessem conduzir à cura de doenças contou com a ordem do rei Felipe II que, em edital de 1570, enviou protomédicos para recolher e publicar estas informações. ${ }^{14}$

Para se ter uma boa idéia do largo recurso à fauna enquanto elemento de receituário em todo o Brasil desde o início do processo colonizador, basta que se verifique a obra História da Província de Santa Cruz (1576), de Pero de Magalhães Gandavo. Na farmacopéia natural cita o emprego da carne da capivara que "he muito saborosa e tam sadia que se manda dar aos enfermos, porque pêra qualquer doença he proveitosa e nam faz mal a nenhuma pessoa". ${ }^{15}$

Capítulo especial na história da ação antrópica merece a relação travada entre colonos e indígenas. Estes, também nisso, foram seus grandes mestres e indispensável apoio. Com o índio ele aprendeu a conhecer a fauna e flora tropical, técnicas de caça (rastrear, imitar a voz dos animais), uso de armas "mudas" (arco e flecha), armadilhas (jirau), remédios, assim como a crença nas entidades míticas da floresta como o curupira. ${ }^{16}$

o Códice Costa Matoso está igualmente repleto de exemplos da ação antrópica dos mineiros sobre a flora e fauna local. Vejamos alguns casos: Um dos pioneiros na ocupação do território mineiro, Bento Fernandes Furtado diz que o ouro era "extraído entre os intervalos do divertimento da caça e outros empregos necessários aos Sertanejos para o alimento e conservação da vida". ${ }^{17}$

Entre 1697-98, durante a primeira crise de fome que assolou a região, o governador Artur de Sá e Menezes noticiara ao rei que "a necessidade

13 Além desses, usava-se pena de quiruá para confecção de flores; pele de veado para botas e vestes; labfermento de anta, de tatu canastra ou de veado para separação da caseína na preparação do queijo; pêlo de macaco guariba para cobertura de selas (tornando maior o número de fêmeas); com a pele da ema fabricava-se perneiras e bolsas para dinheiro, seus ovos serviam de cabaça ou tigela e suas penas para leques; bico de tucano para polvarinhos; os papagaios, por aprenderem a falar, assobiar e cantar eram domesricados. Todos esses exemplos podem ser encontrados in: WIED-NEUWIED, Maximiliano. Viagem ao Brasil. São Paulo: Companhia Editora Nacional, 1958. As obras dos outros viajantes como Richard Burton, Saint Hilaire, Rugendas e Spix \& Martius estão repletas de exemplos semelhantes.

14 WISSENBACH. Maria Cristina Cortez. Gomes Ferreira e os símplices da terra: experiências sociais dos cirurgiões no Brasil colonial. In: FERREIRA, Luís Gomes. Erário Mineral, v.1, p.112s.

15 GANDAVO, Pero de Magalhães. História da província de Santa Cruz. Belo Horizonte: Itatiaia/São Paulo: Edusp, 1980, p.104. Do mesmo autor veja: GANDAVO, Pero de Magalhães. Tratado da terra do Brasil. Belo Horizonte: Itatiaia; São Paulo: Edusp, 1980.

16 HOLANDA, Sérgio Buarque de. Caminhos e fronteiras. Rio de J aneiro: J osé Olympio, 1957.

17 Documento 2. Apud: Códice Costa Matoso. Coleção das notícias dos primeiros descobrimentos das minas na América que fez o doutor Caetano da Costa Matoso sendo ouvidor geral das do Ouro Preto, de que tomou posse em fevereiro de 1749, \& vários papéis. Coord. Luciano Raposo de Almeida Figueiredo e Maria Verônica Campos. v.1. Belo Horizonte: Fundação J oão Pinheiro, 1999, p.171. (Coleção Mineiriana). 
chegou a tal extremo, que [os mineiros] se aproveitaram dos mais imundos animais, e faltando-lhes estes para poderem alimentar a vida, largaram as minas e fugiram para os matos com os seus escravos e sustentaram-se das frutas agrestes que neles achavam". ${ }^{18}$

É sobejamente conhecido da historiografia mineira o episódio da visita de Dom Pedro de Almeida e Portugal à Capitania de São Paulo e Minas do Ouro no ano de 1717. Ao longo da jornada, ofereceram-lhe meio macaco e formigas para refeição, gentileza da qual ele declinou. ${ }^{19}$ Comer formiga Içá (tanajura) é milenar hábito indígena ao qual os paulistas se adaptaram, mas que não agradou ao refinado paladar do nobre português. ${ }^{20}$

O autor anônimo de documento datado de cerca de 1750, é explícito ao dizer que a vida dos homens que andavam pelos sertões de Minas era se alimentar de "todo gênero de caças: antas, veados, macacos, quatis, onças, capivaras, cobras, lagartos, formigas e uns sapinhos que dão pelas árvores, e, outrossim, mais uns bichos muito alvos, que se criam em taquara e paus podres". 21

A captura destes animais passou a ser feita por escravos negros e/ou índios especializados na arte da caça. Na segunda metade do século XVIII, nos Autos de Seqüestro dos bens dos inconfidentes mineiros, dentre os 458 escravos seqüestrados, havia "Pedro Angola, caçador, de trinta anos, que foi avaliado em cento e trinta mil réis", de propriedade de Alvarenga Peixoto.22

Quando Debret chegou ao Brasil nas primeiras décadas do século XIX, pôde presenciar e registrar em suas pranchas a atuação destes escravos, cuja experiência e remontava há séculos. Assim ele descreve o regresso de negros caçadores:

É principalmente na roça que se criam os negros destinados à profissão de caçadores. Aí, preparados desde a adolescência para acompanharem as tropas, ou simplesmente o seu senhor, nas longas e penosas viagens, andam sempre armados de um fuzil, tanto para a sua segurança pessoal como para conseguir víveres durante as paradas indispensáveis, no meio das florestas virgens.

Esse gênero de vida torna-se uma paixão tão forte no negro da roça que ele já não aspira à liberdade senão para entrar na floresta como caçador profissional e entregar-se sem reservas à atração de uma tendência que beneficia ao mesmo tempo seus interesses.

18 SOUZA, Laura de Mello e. Desclassificados do ouro: a pobreza mineira no século XVIII. Rio de J aneiro: Edições Graal, 1982, p.25.

19 Diário da jornada, que fez o Exmo. Sr. D. Pedro desde o Rio de J aneiro athe a cidade de São Paulo, e desta athe as Minas, no ano de 1717. Revista do Serviço do Patrimônio Histórico e Artístico Nacional, Rio de J aneiro, n.3, p.308, 1939.

20 Sobre a história da culinária mineira ver FRIEIRO, Eduardo. Feijão, angu e couve: ensaio sobre a comida dos mineiros. Belo Horizonte: Editora da UFMG, 1966.

21 Documento 6. Apud: Códice Costa Matoso, p.218.

22 Autos de Devassa da Inconfidência Mineira. 2a.ed. Brasília: Câmara dos Deputados/Belo Horizonte: Imprensa Oficial de Minas Gerais, 1980, v.Vl, p.184 e 326. 
Livre então, e já sem temor do chicote, o direito de raciocinar faz dele um fornecedor tão astuto quanto o homem branco cujo gosto conhece; e, perfeitamente consciente do valor de uma peça fina misturada à caça trazida para a cidade, vai oferecê-la de preferência aos cozinheiros de uma casa rica, que lhe pague bem; aliando a inteligência à operosidade ele torna assim sua profissão às vezes muito rendosa. ${ }^{23}$

Todos estes exemplos ratificam a inestimável importância que livros como o Erário mineral de Luís Gomes Ferreira tinham na sociedade mineira, e ajudam a entender como se fazia para ter acesso a estes animais, em geral, difícil de serem capturados, tarefa incumbida aos escravos caçadores, como vimos acima.

Em resumo, quando o homem caça, ele não busca apenas sanar sua fome, mas também se prover de peças de vestuário, elementos simbólicos, utilitários e produtos medicinais. A relação do homem com a fauna silvestre na sociedade mineira adentra ainda o plano religioso ao compor a trama simbólica de oratórios. Num presépio da segunda metade do século XVIII, pertencente ao acervo do Museu da Inconfidência, encontramos um tatu ocupando o lugar originalmente pertencente a outros animais, como pode ser visto na foto abaixo (Figura 1). ${ }^{24}$

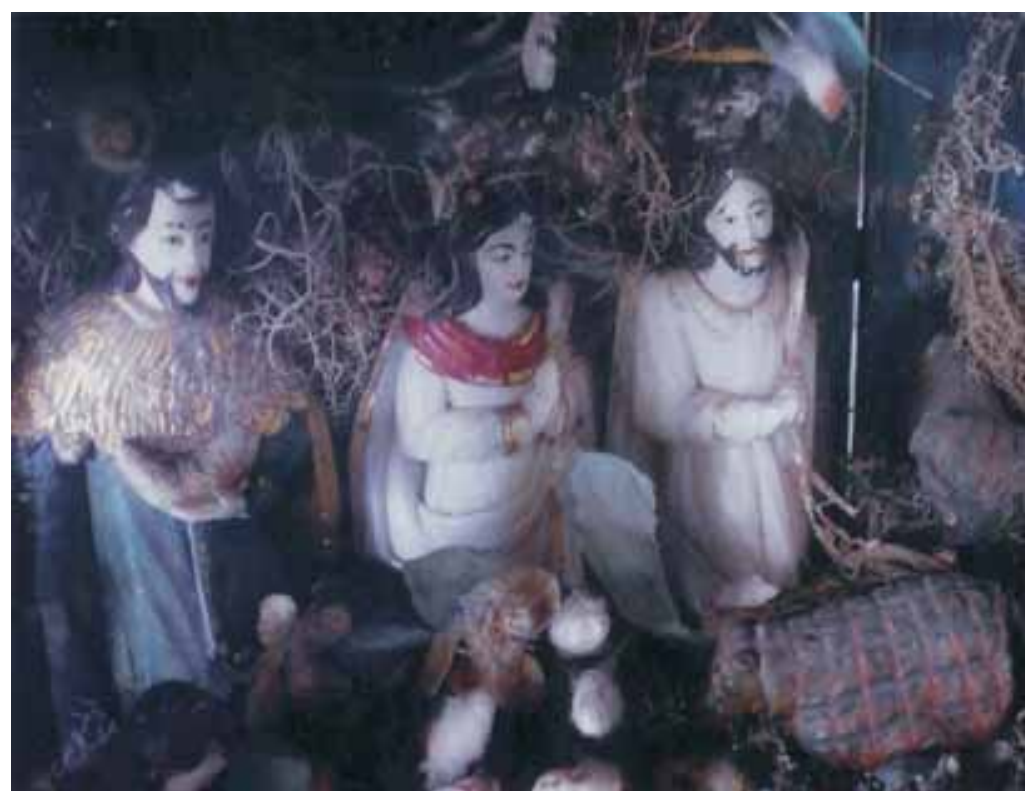

Figura 1: Oratório mineiro do século XVIII. (Foto do autor).

23 DEBRET, J ean Baptiste. Viagem pitoresca e histórica ao Brasil. Trad. e notas Sérgio Milliet. Belo Horizonte: Editora Itatiaia/São Paulo: Edusp, 1978, t.l, p.240s.

24 Número do Inventário: 579. Sua ficha traz as seguintes informações: Nome do objeto: Oratório (com grupo escultórico religioso); título: Cenas da vida de Cristo; autor desconhecido; fabricante desconhecido; dimensões: altura $-0,745 \mathrm{~m}$, largura - 0,325m, profundidade-0,130m; Época/data: século XVIII (2a metade); Material: madeira, pedra (talcita), tintas; técnica: marcenaria e entalhe, escultura, pintura (policromia); Estilo: Rococó, Brasil-colônia. 


\section{Famacopéia Zoológica}

Preocupado adaptar seus conhecimentos à nova realidade ecológica com a qual se deparou, Ferreira enfatizou a ineficácia dos elementos e receitas válidas para a Europa que perdiam muito de suas propriedades terapêuticas no longo trajeto atlântico e no tempo de anos que ficavam acondicionadas nas boticas do litoral ou mesmo do interior. Além disso, mostra-se muito preocupado com os pobres que punham a perder seus poucos cabedais com receitas caras, médicos, cirurgiões e barbeiros inexperientes. Neste novo clima e ambiente, segundo ele, era indispensável empregar os próprios recursos que a natureza oferecia ali, fresco, ao alcance das mãos, com maior força, vigor e, principalmente, mais baratos e de fácil manipulação. Exemplifiquemos com os casos das originais receitas onde emprega o Bugio e a Abelha J ataí, deixando explícita a preocupação do autor em não pairar dúvidas acerca dos animais a serem usados:

Nestas Minas há uns macacos a que chamam barbados, outros lhe chamam bugios, e são uns que tem papo e são preto pelo corpo, e pelo fio do lombo tem o seu cabelo a modo de ruivo e são conhecidos pelo nome de barbados, e pelo papo, de muita gente. ${ }^{25}$

Em falta do mel de Portugal, me parece mais acertado usar do mel de pau das abelhas do Brasil do que do açúcar, porque, deste mel, tenho muita experiência, mas há de ser o mel a que chama J itaí, ou mandassaia, que é o melhor. ${ }^{26}$

Na polêmica pública travada com outro cirurgião em Sabará no ano de 1711, sobre a melhor forma de tratar a fratura de fêmur do escravo de Manuel Gonçalves Loures, assim afirmou: "disse eu que éramos obrigados a curar as doenças conforme a região e o clima, aonde nos achássemos, a razão nos ditasse e a experiência nos ensinasse; porque os autores, quando escreveram, estavam em outras terras mui remotas, e de diferente clima, e não tinham notícia deste". ${ }^{27}$

O clima, assim como os humores produzidos "por razão dos mantimentos e habitação em que assistem e se exercitam, assim os pretos como os brancos" são os responsáveis pelos males. Ou seja, o clima de Minas, por ser "totalmente diferente de todos os mais", 28 exigia a revisão de receitas e postulados tradicionais, assim como a inclusão de elementos da fauna e flora locais.

Antidogmático por excelência, mas sem preterir do devido apoio das autoridades como Hipócrates, Galeno, Paracelso e Curvo Semedo e ou-

25 FERREIRA, Luís Gomes. Erário Mineral, v.1, p.381.

26 FERREIRA, Luís Gomes. Erário Mineral, v.2, p.555.

27 FERREIRA, Luís Gomes. Erário Mineral, v.1, p.471.

28 FERREIRA, Luís Gomes. Erário Mineral, v.1, p.229. 
tros, Ferreira preconizou a inclusão de "ervas, raízes, coisas minerais e de animais que há pelas partes do Brasil e seus sertões, que não deixariam de agradar aos leitores e servirem de muito préstimo à saúde pública". ${ }^{29}$ Nova região, novo clima, novas condições de vida e trabalho e novas doenças necessitam, portanto, de novos remédios, muitos dos quais ele mesmo inventou. Para muitos, como veremos a seguir, os animais eram componentes essenciais.

Ao longo de sua obra, Ferreira apresentou grande diversidade de receitas nas quais, partes ou animais silvestres inteiros encontrados em Minas Gerias, entram como ingredientes principais ou exercem papéis complementares. É preciso frisar listamos todos as enfermidades para as quais o autor fez uso dos animais e/ou seus órgãos, tecidos e produtos e não todas as receitas, pois em algumas variam apenas os elementos complementares.

A referência genérica de Ferreira ao lobo, veado, cágado, aves do monte, jacaré, não impediu sua inclusão na Tabela haja vista sua ocorrência em Minas. Acreditamos que cágado seja uma alusão à tartaruga; lobo pode tratar-se do lobo-guará (Crysocion brachyurus), o veado de manchas brancas, o veado catingueiro (Mazama gouazoubira) e assim por diante. Esta inferência é legítima devido à sua explícita preocupação em recorrer à realidade que o cercava, permanecendo assim, fiéis a nosso corte espacial e às intenções do cirurgião.

Para melhor organização do texto, os animais utilizados, a indicação e o receituário serão apresentados na Tabela 1 . A Tabela 2 e Gráfico 1 sintetizam e quantificam os percentuais por classes dos 27 animais empregados em sua farmacopéia zoológica. A Tabela 3 sintetiza a relação doença/animais.

29 FERREIRA, Luís Gomes. Erário Mineral, v.1, p.226. (grifo meu) 
Tabela $\mathbf{1}^{30}$

\begin{tabular}{|c|c|c|}
\hline Animal & $\begin{array}{l}\text { Órgão, } \\
\text { tecido ou } \\
\text { produto }\end{array}$ & Indicação e Receituário \\
\hline \multirow{14}{*}{$\begin{array}{l}\text { Abelha } \\
\text { J ataí }\end{array}$} & \multirow{12}{*}{ Mel } & $\begin{array}{l}\text { Icterícia: “Rabao com açúcar (...) e muito melhor será com o } \\
\text { mel”,p.555. }\end{array}$ \\
\hline & & $\begin{array}{l}\text { Obstrução do fígado: "Ihe ajunte, de oximel, duas onças, e } \\
\text { se guarde para uso", p.284. }\end{array}$ \\
\hline & & $\begin{array}{l}\text { Belidas e cicatrizes: "também usa de água destilada de mel } \\
\text { virgem com bom sucesso", p. } 343 \text {. }\end{array}$ \\
\hline & & $\begin{array}{l}\text { Gangrenas e Chagas podres: "mel dezesseis onças", } \\
\text { p.349. }\end{array}$ \\
\hline & & $\begin{array}{l}\text { Asma: "tudo se coza em quatro canadas de águamel, que é } \\
\text { a água adoçada com mel" , p.370. }\end{array}$ \\
\hline & & $\begin{array}{l}\text { Para fazer nascer cabelo na cabeça ou em outras partes: } \\
\text { "Também untar a parte com mel misturado com pós de } \\
\text { moscas muitas vezes", p.375. }\end{array}$ \\
\hline & & $\begin{array}{l}\text { Para concepção: “almécega (...) mel puro duas libras", } \\
\text { p.419. }\end{array}$ \\
\hline & & $\begin{array}{l}\text { Dores e fraqueza do estomago: "misturando com sumo de } \\
\text { picão ou (...)", p.556. }\end{array}$ \\
\hline & & $\begin{array}{l}\text { Tumores ou inchaços de humor frio que nascem nas costas } \\
\text { das mãos: "Fervam um pouco de mel de pau do melhor", } \\
\text { p.590. }\end{array}$ \\
\hline & & $\begin{array}{l}\text { Papos: “(...) como o mel se não seca com facilidade, pode- } \\
\text { se meter um dia de permeio", p. } 593 \text {. }\end{array}$ \\
\hline & & $\begin{array}{l}\text { Chagas: "se tocarão com xarope rosado, ou mel de pau", } \\
\text { p.618. }\end{array}$ \\
\hline & & Envenenamento: (ópio) “mel com azeite-rosado”, p.672. \\
\hline & \multirow{2}{*}{ Cera } & $\begin{array}{l}\text { Tirar calos: "o ungüento feito de cera da terra, que é a das } \\
\text { abelhas silvestre das Minas e do Brasil", p.376. }\end{array}$ \\
\hline & & $\begin{array}{l}\text { Rachadura nos calcanhares: "se lhe ponha o ungüento feito } \\
\text { de cera da terra com azeite", p.390. }\end{array}$ \\
\hline Andorinha & $\begin{array}{l}\text { Pedra do } \\
\text { ventre }\end{array}$ & $\begin{array}{l}\text { Gota-coral: "tiradas no minguante da Lua e trazidas ao } \\
\text { pescoço ou atadas no bucho do braço, livra dos ditos } \\
\text { acidentes", p.434. }\end{array}$ \\
\hline Aranha & Teia & $\begin{array}{l}\text { Para membros que estiverem com pouco movimento, } \\
\text { paralisia ou resfriamento: "porque não tendo mais que clara } \\
\text { de ovo e teias de aranha para tomar o sangue (...) parou o } \\
\text { sangue, não sendo pouco", p.565. }\end{array}$ \\
\hline
\end{tabular}

30 Na Tabela 1, não empregamos o nome científico dos animais citados devido à forma genérica a que Luís Gomes Ferreira a eles se refere, tornando impossível determinar com precisão a espécie de vários deles. Da mesma forma, não faremos também a atualização nosológica, ficando o mais fiel possível à maneira como o autor classificava e descrevia as doenças, ferimentos, etc., salvo no que foi necessário à sua inteligibilidade. 


\begin{tabular}{|c|c|c|}
\hline Animal & $\begin{array}{l}\text { Órgão, } \\
\text { tecido ou } \\
\text { produto }\end{array}$ & Indicação e Rec eituário \\
\hline $\begin{array}{l}\text { Aves do } \\
\text { Monte }\end{array}$ & Carne & $\begin{array}{l}\text { Obstrução do fígado: «também poderá comer (...) aves do } \\
\text { monte", p } 288 .\end{array}$ \\
\hline $\begin{array}{l}\text { Bicho-de- } \\
\text { contas* }\end{array}$ & Inteiro & $\begin{array}{l}\text { Surdez e zunimento nos ouvidos: "tomai (...) quarenta } \\
\text { bichos-de-conta, chamados milipedes", p.359. }\end{array}$ \\
\hline \multirow{2}{*}{$\begin{array}{l}\text { Bugio } \\
\text { (Macaco } \\
\text { Barbado } \\
\text { ou macaco } \\
\text { Guariba) }\end{array}$} & $\begin{array}{l}\text { Bola do } \\
\text { quadril } \\
\text { (conta de } \\
\text { macaco) }\end{array}$ & $\begin{array}{l}\text { Almorreimas (Hemorróidas): "estando ainda vivos, se lhes } \\
\text { tira aquela noz redonda a modo de bolazinha, que encai- } \\
\text { xa no quadril na cova onde joga a perna e há de ser o da } \\
\text { perna esquerda; esta bolazinha, (...), se aperfeiçoa e fura } \\
\text { para trazer atada no braço esquerdo, de modo que toque } \\
\text { na carne (...)", p.382. }\end{array}$ \\
\hline & Pele & $\begin{array}{l}\text { Dores antigas causadas de flatos ou de humores frios: } \\
\text { "Esfregar a parte dolorosa com ungüento (...) de bicuíba } \\
\text { (...) cobrindo a parte com uma pele de macaco chamado } \\
\text { guariba", p.403. }\end{array}$ \\
\hline \multirow{2}{*}{ Cágado } & Cinza & $\begin{array}{l}\text { Para tirar os sinais e covas das bexigas: "meia onça de } \\
\text { fezes-de-ouro lavadas, outra meia de cinza de cágados", } \\
\text { p.355 }\end{array}$ \\
\hline & Sangue & $\begin{array}{l}\text { Para não nascer cabelo: "Quem esfregar a parte, depois de } \\
\text { tirados os cabelos, com sangue de cágado conseguirá o } \\
\text { não tornarem a nascer", p.374. }\end{array}$ \\
\hline Cantáridas & Pó & $\begin{array}{l}\text { Para os calos das fontes: "Molhem um grão novo, antes de } \\
\text { o meterem na fonte, na saliva da boca, e se envolva em pós } \\
\text { de cantáridas e se use por vinte e quatro horas", p.377. }\end{array}$ \\
\hline \multirow{10}{*}{ Cobra } & Unto & $\begin{array}{l}\text { Dores antigas ou inchaços de humor frio que nascem nas } \\
\text { juntas: "E também o unto de cobra faz o mesmo" (cf. a } \\
\text { receita do lobo), p.403. }\end{array}$ \\
\hline & Pele & $\begin{array}{l}\text { Expulsar a párea retida após o parto: "aplicada sobre o } \\
\text { pecten", p.418. }\end{array}$ \\
\hline & $\begin{array}{l}\text { Cascavel } \\
\text { (o guizo da } \\
\text { cobra) }\end{array}$ & $\begin{array}{l}\text { Gota-coral (Epilepsia): "o cascavel da cobra do Brasil } \\
\text { trazido debaixo do sovaco livra dos tais acidentes, tudo por } \\
\text { virtude oculta que Deus Ihe deu", p. } 434 \text {. }\end{array}$ \\
\hline & \multirow{7}{*}{$\begin{array}{l}\text { Triaga } \\
\text { (remédio } \\
\text { à base de } \\
\text { trocisco de } \\
\text { víbora) }\end{array}$} & $\begin{array}{l}\text { Envenenamento por sarro de cachimbo: "triaga magna } \\
\text { desfeita em vinho", p.613. }\end{array}$ \\
\hline & & $\begin{array}{l}\text { Envenenamento por ópio: "beba triaga desfeita em vinho", } \\
\text { p.672. }\end{array}$ \\
\hline & & $\begin{array}{l}\text { Mordedura de cão danado: "fazem-se alhos e cebolas com } \\
\text { triaga magna", p.679. }\end{array}$ \\
\hline & & Chagas do Escorbuto: "triaga magna duas oitavas", p.695. \\
\hline & & $\begin{array}{l}\text { Mordedura de víbora e mais cobras venenosas: "triaga pisa- } \\
\text { da ou misturada com folhas de arruda", p.681. }\end{array}$ \\
\hline & & Chagas do Escorbuto: "triaga magna duas oitavas", p.695. \\
\hline & & $\begin{array}{l}\text { Mordedura de víbora e mais cobras venenosas: "triaga pisa- } \\
\text { da ou misturada com folhas de arruda", p.681. }\end{array}$ \\
\hline
\end{tabular}




\begin{tabular}{|c|c|c|}
\hline Animal & $\begin{array}{l}\text { Órgão, } \\
\text { tecido ou } \\
\text { produto }\end{array}$ & Indicação e Receituário \\
\hline \multirow[b]{2}{*}{ Cobra } & $\begin{array}{l}\text { Álcool de } \\
\text { carne }\end{array}$ & $\begin{array}{l}\text { Envenenamento: "tomem meia oitava, ou uma, de álcool de } \\
\text { carne de víbora em vinho generoso ou de malvasia", p.674. }\end{array}$ \\
\hline & $\begin{array}{l}\text { Inteira ou } \\
\text { cabeça }\end{array}$ & $\begin{array}{l}\text { Mordedura de víbora e mais cobras venenosas: "se pude- } \\
\text { rem apanhar a mesma víbora, se pise e ponha na mordedu- } \\
\text { ra, ou cabeça de víbora seca e posta nela", p. } 682 \text {. }\end{array}$ \\
\hline Coruja & Ovos & $\begin{array}{l}\text { Para os bêbados aborrecerem o vinho: "deitarem de infusão } \\
\text { um ovo de uma coruja, mal assado, feito em talhadinhas } \\
\text { miúdas", p.445. }\end{array}$ \\
\hline Escorpião & Óleo & $\begin{array}{l}\text { Envenenamento: "untem a testa, frontes (...) com óleo de } \\
\text { escorpiões composto e tomem algumas pingas pela boca", } \\
\text { p.673. }\end{array}$ \\
\hline Formiga & Ovos & $\begin{array}{l}\text { Surdez e zunimento nos ouvidos: "tomai trezentos ovos de } \\
\text { formigas", p.359s. }\end{array}$ \\
\hline $\begin{array}{l}\text { Inhaúma } \\
\text { (Unicórnio) }\end{array}$ & $\begin{array}{l}\text { Corno e } \\
\text { esporões } \\
\text { das asas }\end{array}$ & $\begin{array}{l}\text { Envenenamento e picada de cobras "feitos em pó, têm } \\
\text { virtude bezoártica muito excelente", p.674. }\end{array}$ \\
\hline $\begin{array}{l}\text { Jacaré } \\
\text { (lagarto) }\end{array}$ & $\begin{array}{l}\text { Inteiro (sem } \\
\text { entranha) }\end{array}$ & $\begin{array}{l}\text { Tirar dente sem uso de ferro: "Os pós do lagarto, seco no } \\
\text { forno em forma que se possam fazer, aplicados à roda do } \\
\text { dente que quiserem tirar fará desunir a carne dele e se tirará } \\
\text { com facilidade", p.326. }\end{array}$ \\
\hline Lagartixa & Inteira & $\begin{array}{l}\text { Fazer crescer as bexigas que estiverem alastradas: "Frijam } \\
\text { três ou quatro lagartixas vivas em meia canada de azeite } \\
\text { velho, até que as lagartixas se torrem, e, coado este óleo, } \\
\text { se guarde para com ele, quente, esfregar os lugares em } \\
\text { que estiverem as bexigas alastradas", p. } 356 \text {. }\end{array}$ \\
\hline \multirow{5}{*}{ Lebre } & \multirow{3}{*}{ Pêlo } & $\begin{array}{l}\text { Estancar sangramento do nariz: "cabelos de lebre cortados } \\
\text { miúdos }(\ldots) \text { ", p.324. }\end{array}$ \\
\hline & & $\begin{array}{l}\text { Estancar sangue de artéria cortada: "de magistério de ópio } \\
\text { um escrópulo, cabelos de lebre cortados miúdos, e clara de } \\
\text { ovo a que baste; faz massa e dela pílulas pequenas, que } \\
\text { mete na boca do vaso as que batas", p.348. }\end{array}$ \\
\hline & & $\begin{array}{l}\text { Estancar fluxo de sangue de artéria cortada: "cabelos de } \\
\text { lebre cortados miúdos (...) faz massa e dela pílulas peque- } \\
\text { nas, que mete na boca do vaso as que bastam", p.348. }\end{array}$ \\
\hline & Coalho & $\begin{array}{l}\text { Para Concepção: "cozam coalho de lebre em leite de ca- } \\
\text { bras, do qual beberá a mulher quando se for deitar", p.419. }\end{array}$ \\
\hline & Sesso & $\begin{array}{l}\text { Para quem mija na cama estando dormindo: "feita em pó, } \\
\text { bebido no mesmo vinho", p.438. }\end{array}$ \\
\hline Lobo & Unto & $\begin{array}{l}\text { Dores antigas ou inchaços de humor frio que nascem nas } \\
\text { juntas: "o unto de lobo, pisado com as constas de uma faca } \\
\text { e misturado...", p.403. }\end{array}$ \\
\hline Lontra & Pele & $\begin{array}{l}\text { Membros que estiverem com pouco movimento, paralisia } \\
\text { ou resfriamento: "e depois da parte bem fomentada, se } \\
\text { cobrirá com alguma pele de bicho macia, como de lontra, } \\
\text { ou outra semelhante", p.560. }\end{array}$ \\
\hline
\end{tabular}




\begin{tabular}{|c|c|c|}
\hline Animal & $\begin{array}{l}\text { Órgão, } \\
\text { tecido ou } \\
\text { produto }\end{array}$ & Indicação e Receituário \\
\hline \multirow{3}{*}{ Minhoca } & \multirow{3}{*}{ Inteira } & Panarício: “minhocas machucadas”, p.365. \\
\hline & & $\begin{array}{l}\text { Deslocação do ombro e do quadril: "se poderá usar do óleo } \\
\text { (...) de minhocas", p.453. }\end{array}$ \\
\hline & & $\begin{array}{l}\text { Deslocações: "emolientes de óleo de amêndoas doces e de } \\
\text { minhocas", p. } 457 \text {. }\end{array}$ \\
\hline Morcego & Sangue & $\begin{array}{l}\text { Para não nascer cabelo: "Arrancados os cabelos e untar } \\
\text { aquela parte com o sangue de um morcego", p.374. }\end{array}$ \\
\hline \multirow{3}{*}{ Mosca } & Larva & $\begin{array}{l}\text { Para caírem os cabelos e não to marem a nascer: "Tomem } \\
\text { uma pouca de came de vaca, ponham-na aonde apodreça } \\
\text { e se encha de bichos, estes bicho se sequem ao fogo até } \\
\text { que se possam fazer em pó (...) e poreis isto no lugar que } \\
\text { quiserdes pelar e que fique sem cabelo", p.374. }\end{array}$ \\
\hline & \multirow{2}{*}{ Inteira } & $\begin{array}{l}\text { Para fazer nascer cabelo na cabeça ou em outras partes: } \\
\text { "Também untar a parte com mel misturado com pós de } \\
\text { moscas muitas vezes", p.375. }\end{array}$ \\
\hline & & $\begin{array}{l}\text { Tirar aranha que entrou no ouvido: "chegareis ao ouvido } \\
\text { uma mosca pegando-lhe pelas pernas, porque, com o zuni- } \\
\text { do das asas, logo a aranha sairá a pescá-la", p.393. }\end{array}$ \\
\hline Percevejo & Inteiro & $\begin{array}{l}\text { Para lançar a criança que estiver morta no ventre e para } \\
\text { lançar as páreas (placenta): "Pisem percevejos e se metam } \\
\text { na boca da madre, ou se bebam três pisados e desfeitos } \\
\text { em vinho ou caldo-de-galinha", p.336. }\end{array}$ \\
\hline Perdiz & Inteira & $\begin{array}{l}\text { Resfriamento: "Pela boca se terá grande cuidado de sustan- } \\
\text { ciar e alimentar o doente com bons caldos-de-galinha ou de } \\
\text { perdiz", p. } 657 \text {. }\end{array}$ \\
\hline \multirow{3}{*}{ Rã } & $\begin{array}{l}\text { Enxúndia } \\
\text { (banha) }\end{array}$ & $\begin{array}{l}\text { Tirar dente sem uso de ferro: "Ponham em cima do dente } \\
\text { que quiserem tirar", p.326. }\end{array}$ \\
\hline & Sangue & $\begin{array}{l}\text { Para não nascer cabelo: "Esfregar a cabeça ou outra qual- } \\
\text { quer parte aonde não quiserem que nasça cabelo com o } \\
\text { sangue de uma rã de ribeira corrente" , p.374. }\end{array}$ \\
\hline & $\begin{array}{l}\text { Sperma } \\
\text { Ranarum }\end{array}$ & $\begin{array}{l}\text { Queimadura de pólvora na cara: "lave-se nove vezes ou } \\
\text { mais em água de esperma ranarum", p.367. }\end{array}$ \\
\hline \multirow[t]{2}{*}{ Rato } & $\begin{array}{l}\text { Inteiro } \\
\text { (filhotes) }\end{array}$ & $\begin{array}{l}\text { Para os surdos que deitam matéria ou humores pelos ouvi- } \\
\text { dos: "(...) frigir quatro ou cinco ratinhos vivos acabados de } \\
\text { nascer, ou nascidos de dois ou três dias, em oito onças de } \\
\text { óleo de arruda (...)", p.359. }\end{array}$ \\
\hline & Inteiro & $\begin{array}{l}\text { Para rachadura nos calcanhares: "Abram pela barriga ratos } \\
\text { vivos e se ponham logo em quentes, repetindo isto muitas } \\
\text { vezes", p. } 390 .\end{array}$ \\
\hline
\end{tabular}




\begin{tabular}{|c|c|c|}
\hline Animal & $\begin{array}{l}\text { Órgão, } \\
\text { tecido ou } \\
\text { produto }\end{array}$ & Indicação e Receituário \\
\hline \multirow{3}{*}{ Sapo } & Inteiro & $\begin{array}{l}\text { Conter fluxo de sangue de ferida: "metam em uma bolsa } \\
\text { de escarlate pó de sapo e se meta no sovaco do braço da } \\
\text { parte donde sair o sangue, ou se tenha na mão até que } \\
\text { aqueça", p.323. }\end{array}$ \\
\hline & \multirow{2}{*}{$\begin{array}{l}\text { Osso da } \\
\text { coxa }\end{array}$} & $\begin{array}{l}\text { Conter fluxo de sangue do nariz: "metido no nariz, no mes- } \\
\text { mo instante, faz parar o fluxo do sangue dele", p. } 323 \text {. }\end{array}$ \\
\hline & & $\begin{array}{l}\text { Tirar dor de dente: "Também é certo tirar este osso a dor } \\
\text { do dente que doer, tocando-o ou esfregando-o com ele", } \\
\text { p.323. }\end{array}$ \\
\hline \multirow{5}{*}{ Veado } & Carne & $\begin{array}{l}\text { Obstrução do fígado: "também poderá comer (...) veados", } \\
\text { p.288. }\end{array}$ \\
\hline & $\begin{array}{l}\text { Ponta de } \\
\text { chifre }\end{array}$ & $\begin{array}{l}\text { Quando a madre sai fora do lugar: "e beba também pó de } \\
\text { pontas de veado", p.439. }\end{array}$ \\
\hline & \multirow[t]{3}{*}{$\begin{array}{l}\text { Pedra } \\
\text { Cordial* }\end{array}$} & $\begin{array}{l}\text { Envenenamento: "é o melhor bezoártico do mundo (...), } \\
\text { roçando ou limando dela meia oitava para cada bebida em } \\
\text { licor conveniente", p.674. }\end{array}$ \\
\hline & & Mordeduras venenosas: Idem, p.674. \\
\hline & & Febres malignas: Idem, p.674. \\
\hline
\end{tabular}

* Encontrada no bucho do veado que tem manchas brancas.

** "Pequeno crustáceo que vive entre pedras ou em lugares sombrios e úmidos, também chamados milípedes" (FERREIRA, Luís Gomes. Erário Mineral, v.2, p.777). Trata-se do Oniscus asellus, vulgarmente conhecido como "tatuzinho de jardim".

Tabela 2

\begin{tabular}{|c|c|}
\hline Classes & Total \\
\hline Mamíferos & 07 \\
\hline Aves & 05 \\
\hline Insetos & 05 \\
\hline Répteis & 04 \\
\hline Aracnídeos & 02 \\
\hline Anfíbios & 02 \\
\hline Oligoqueta & 01 \\
\hline Crustáceo & 01 \\
\hline Total & 27 \\
\hline
\end{tabular}

\section{Gráfico 1}

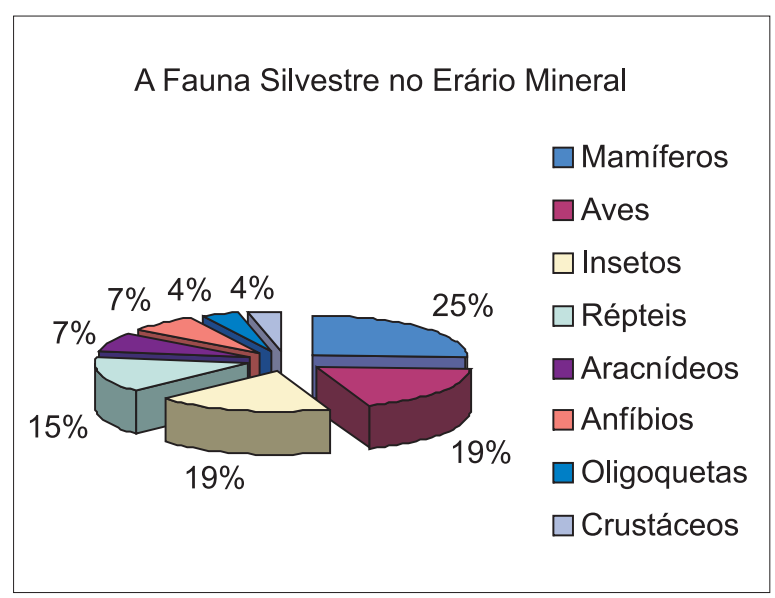


Tabela 3

\begin{tabular}{|l|l|}
\hline \multicolumn{1}{|c|}{ Classe } & \multicolumn{1}{c|}{ Doenças } \\
\hline Mamíferos & $\begin{array}{l}\text { Relacionadas aos órgãos internos (fígado, útero e ouvido) envenena- } \\
\text { mento, mordeduras venenosas, febres malignas, conter fluxo de sangue, } \\
\text { dermatológico, dores, hemorróidas, locomoçao. }\end{array}$ \\
\hline Aves & $\begin{array}{l}\text { Obstrução do fígado, epilepsia, alcoolismo, resfriamento, envenenamen- } \\
\text { to e picada de cobras. }\end{array}$ \\
\hline Insetos & $\begin{array}{l}\text { Relacionadas aos órgãos internos (fígado, pulmão, ouvido, estomago), } \\
\text { capilares, dermatológicos, envenenamento, tireóide, parto e reprodução. }\end{array}$ \\
\hline Répteis & $\begin{array}{l}\text { Relacionadas à saúde bucal, bexigas (varíola), dermatológicas, dores, } \\
\text { parto, epilepsia, envenenamento hidrofobia e escorbuto. }\end{array}$ \\
\hline Aracnídeos & Auxiliar no tratamento de feridas, locomoção e envenenamento. \\
\hline Anfíbios & Saúde bucal e dermatológica. \\
\hline Oligoqueta & Panarício e deslocamento. \\
\hline Crustáceo & Auditivas. \\
\hline
\end{tabular}

Dentre os animais empregados no Erário Mineral, destacaram-se os mamíferos (25\%); são eles: veado, lebre, rato, macaco, morcego, lobo e lontra. Não estaríamos muito distanciados da verdade se afirmássemos que esta preferência pode ser explicada pela existência de "algumas", características fisiológicas mais próximas às do homem, também mamífero, quando comparado às outras classes de animais: lactação e pêlos, por exemplo. No caso do macaco, esta semelhança é ainda mais evidente.

É também aos mamíferos que se recorreu para o combate ao maior número de doenças (cf. Tabela 3). Embora tenha havido esta preponderância, não observamos nenhuma especialização, pois as doenças por eles combatidas se repetem nas outras classes de animais.

É importante frisar que Ferreira não foi o único a recorrer a "fauna mineira". Sabemos que no rol dos medicamentos que J osé Luiz Rebelo empregou em seus escravos, datado de 1789, constavam ''maná', 'ungüento de basilicão', 'cantáridas' em pó (...)'”. ${ }^{31}$ Da mesma forma, o furriel Manoel Lopes Saraiva remeteu uma carta ao governador de Minas Gerais no dia 18 de junho de 1772, onde determinava que enviasse para Portugal, além do caderno dos remédios dos sertanejos, "exemplares de plantas e animais das Minas, sendo que 'todos os animais depois de se lhe extrair as entranhas e tripas, conservando-se em aguardente ou qualquer outro aperito' (...)". Segundo o autor, este saber interessava à Coroa, pois se tratava de "uma

31 GROSSI, Ramon Fernandes. A arte de curar: uma contribuição para o estudo da medicina na capitania de Minas (1750-1808). Cronos: Revista de História, Pedro Leopoldo, Faculdades Integradas Pedro Leopoldo, n.8, p.141-164, $151,2005$. 
tentativa de expropriação da legitimidade desse saber popular". ${ }^{32}$ Ou seja, estes exemplos demonstram que os animais eram efetivamente usados pelos mineiros no tratamento de enfermidades.

A própria obra de Luís Gomes Ferreira, que não é apenas um apanhado de receituários, mas um relato de sua vasta experiência demonstra, através de casos concretos, o efetivo emprego destes elementos de origem animal no cotidiano cuidado da saúde dos habitantes na Minas setecentista.

Ao se levar em conta as características da arte médica do período que ora analisamos, Carneiro lembrou com pertinência que "(...) os metais, as plantas, os animais e as pedras foram criados para satisfazer as necessidades do homem (...). Entre os serviços prestados pela natureza ao homem está o de fornecer as substâncias que combatem os venenos, a podridão e a pestilência". ${ }^{33}$ Ou seja, além de outras finalidades, Deus formou-os também para uso medicinal.

\section{Conclusões}

Seria grave equívoco supor que o recurso a elementos hoje considerados "bizarros" seja fruto de barbárie e ignorância. Para o homem do século XVIII não havia nada de "exótico" nestes medicamentos, além de serem os únicos recursos possíveis à maioria da gente pobre. Ademais, Ferreira assegura que "inimigos fortes não se vencem com armas fracas". ${ }^{34}$

Antropologicamente, o sentimento que explica seu emprego para manter ou recobrar da saúde é fruto do desejo humano de adiar a morte. No século XVIII, saber médico e religião caminhavam juntos para amenizar o sofrimento e fornecer a esperança de cura/graça. 0 uso de medicamentos era acompanhado de orações, promessas, simpatias e feitiços. Alcançada a cura/graça, o fiel materializava seu agradecimento nos ex-votos. Não obstante, no embate pela definição de campos de competência, Igreja e medicina formavam um único exército na cruzada contra feiticeiros, curandeiros e parteiras - combate nem sempre glorioso.

Somente na segunda metade do século XVIII, com a reforma da Universidade de Coimbra em 1772, que a arte médica portuguesa passou por mudanças mais profundas. A partir de então, "Recomendações de exorcismos passam a não ser mais encontradas nos livros de medicina". 350 mesmo ocorreu, paulatinamente, com os produtos de origem animal e humana.

32 GROSSI, Ramon Fernandes. A arte de curar, p.157.

33 CARNEIRO, Henrique Soares. Filtros, mezinhas e triacas, as drogas no mundo moderno. São Paulo: Xamã, 1994, p.84s. Do mesmo autor veja: CARNEIRO, Henrique Soares. Amores e sonhos da flora: afrodisíacos e alucinógenos na botânica e na farmácia. São Paulo: Xamã, 2002.

34 FERREIRA, Luís Gomes. Erário Mineral, v.1, p.238.

35 RIBEIRO, Márcia Moisés. A ciência dos trópicos: a arte médica no Brasil do século XVIII. São Paulo: Hucitec, 1997, p.136. Leia ainda FIGUEIREDO, Betânia Gonçalves. A arte de curar: cirurgiões, médicos, boticários e curandeiros no século XIX em Minas Gerais. Rio de J aneiro: Vício de leitura, 2002. 
Quanto à crença no maravilhoso, esta sofreu muitas metamorfoses, mas permanece renitente no imaginário social com diferentes intensidades.

Predador supremo e onívoro, o Homo sapiens sapiens que veio para Minas em busca do ouro, comércio, atividades agro-pecuárias ou qualquer outra, precisou satisfazer suas necessidades vitais: alimentar-se, vestir-se, habitar, defender-se da natureza hostil e curar-se para poder produzir e se reproduzir. Sua posição erétil associada ao uso da razão, à ilimitada capacidade de criar e aperfeiçoar instrumentos e ao domínio do fogo (que o próprio Ferreira ensina a fazer à maneira dos indígenas) ${ }^{36}$ determinaram a eficácia de sua ação, sobrevivência e domínio do meio. Para isso, derrubou e queimou a mata, caçou os animais dos quais se alimentou e vestiu, domesticou alguns, eliminou aqueles que o ameaçavam e lhe causavam prejuízos na plantação e rebanho e produziu remédios feitos a partir destes mesmos animais que caçou.

Como frisou Ginzburg, "por milênios o homem foi caçador". ${ }^{37}$ Através de gerações e gerações ele transmitiu esse "patrimônio cognoscitivo". Foi na sociedade de caçadores que, segundo o autor, se deu o "gesto talvez mais antigo da história intelectual do gênero humano: do caçador agachado na lama, que escruta as pistas da presa", nascendo daí, "a própria idéia de narração". Neste "patrimônio" está incluso tanto suas habilidades (rastrear, farejar, identificar) quanto o conhecimento farmacológico da fauna silvestre. Patrimônio que Luís Gomes Ferreira transmitiu através de sua prática e da tradição escrita.

Thompson escreveu, com suma precisão, a história da sangrenta Lei Negra de $1723 .{ }^{38}$ Ao violar o direito costumeiro, gerou larga insatisfação nos ingleses mais humildes, condenados à prisão, degredo ou morte por abaterem animais, sobretudo veados (presa específica da realeza), por qualquer pretexto, nas reservas de caça, florestas, parques e cercamentos. Do outro lado do Canal da Mancha, a interdição ao direito de caçar também esteve na raiz do movimento revolucionário francês de 1789.

Luís Gomes Ferreira redigiu sua obra quando a preocupação com a preservação da natureza era essencialmente utilitária. ${ }^{39}$ Q uando na Europa e no Brasil caçar era hábito disseminado e a relação do homem com a doença era permeada pela magia e religiosidade - citemos, p. ex., os reis taumaturgos e a escrófula, brumas do medievo ainda não completamente

36 FERREIRA, Luís Gomes. Erário Mineral, v.1, p.338.

37 GINZBURG, Carlo. Mitos, emblemas, sinais: morfologia e história. Trad. Federico Carotti. São Paulo: Companhia das Letras, 1989, p.151s.

38 THOMPSON, Edward Palmer. Senhores e caçadores: a origem da lei negra. Trad. Denise Bottmann. Rio de J aneiro: Paz e Terra, 1987. Sobre o tema do direito costumeiro é indispensável e leitura de outra obra do mesmo autor: Costumes em comum: Estudos sobre a cultura popular tradicional. São Paulo, Companhia das Letras, 1998.

39 Sobre esta postura diante do meio natural, cf. PADUA, J osé Augusto. Mata atlântica: uma antiga história de devastação. Nossa História, Rio de J aneiro, Biblioteca Nacional, ano I, n.6, p.14-20, 17, 2004. 
dissipadas e o Brasil vivenciava seu processo de civilização e sifilização, para recordarmos a máxima de Freyre. ${ }^{40}$

Se a morte é o destino natural de todo ser vivo, "o que é novo é a extensão pela qual uma espécie, Homo sapiens, tem sido responsável por extinções recentes e por ameaçar muitas formas de vida". ${ }^{41}$

Warren Dean, estima que a mineração, a lavoura e a pecuária no sudeste "podem ter eliminado, durante o século XVIII, outros 30 mil km²" da Mata Atlântica; dentre este percentual, a mineração "teria revirado 4 mil km²".42 Em 1750, Bento Fernandes Furtado já prenunciara o gradual processo de devastação da flora e extinção da fauna mineira: "e os campos e montanhas já estéreis de caças e víveres silvestres, que o muito povo que por todas as partes penetrava tinha destruído e consumido". ${ }^{43}$

0 avanço do desmatamento da floresta nativa colocava o homem em contato com a fauna silvestre ao adentrar seu habitat, e com isso, a expulsão e extinção de diversos espécimes por diferentes motivos como acabamos de demonstrar. Doente - seja branco, negro, índio ou mestiço; escravo, forro ou livre; rico ou pobre; clérigo ou leigo; homem, mulher e criança - para manter e recobrar a saúde, o homem recorreu tanto ao poder do maravilhoso quanto à força preventiva e curativa de elementos naturais, dentre eles, os de origem animal.

Esta luta pela conservação da saúde e sobrevivência nos três séculos de ocupação de Minas Gerais também pode ser considerada como um dos fatores que colaboraram para a extinção de várias espécies e a ameaça a outras. É importante lembrar que a comarca de Vila Rica possuía, sozinha, em meados de 1720, cerca de 100 mil pessoas "dobro da população da Bahia, sede do Vice-Reinado, triplo da do Rio de J aneiro e quádruplo da de São Paulo". ${ }^{44} \mathrm{~A}$ população total de Minas foi estimada em aproximadamente 320 mil em 1770, chegando a 514.108 em 1812. Muitas vezes a esperança da vida destes milhares e milhares de pessoas esteve condicionada à morte de diversos exemplares da fauna silvestre que empregaram em suas receitas médicas.

À medida que o homem se civilizou foi abandonando o hábito e concepção cultural, bíblica inclusive, ${ }^{45}$ que 0 colocava acima e senhor das

40 Sobre este tema veja o clássico BLOCH, Marc. Os reis taumaturgos: o caráter sobrenatural do poder régio, França e Inglaterra. Trad. J úlia Mainard. São Paulo: Companhia das Letras, 1993.

41 POUGH, F. Harvey et all. A vida dos vertebrados. São Paulo: Atheneu, 1993, p.817.

42 DEAN, Warren. A ferro e fogo: a história e a devastação da mata atlântica brasileira. Trad. Cid Knipel Moreira. São Paulo: Companhia das Letras, 1996, p.131 e 115.

43 Documento 2. Apud: Códice Costa Matoso, p.174.

44 J ARDIM, Márcio. A inconfidência mineira: uma síntese factual. Rio de J aneiro: Bibliex, 1989, p. 24.

45 "E criou Deus o homem à sua imagem: ele criou à imagem de Deus, macho e fêmea os criou. Deus os abençoou e disse: crescei, e multiplicai-vos e enchei a terra, e sujeitai-a, e dominai sobre os peixes do mar, e sobre as aves do céu, e sobre os animais que se movem sobre a terra. Disse também Deus: Eis aí vos dei eu todas as ervas, que dão as suas sementes sobre a terra; e todas as árvores, que tem em si mesmas a semente do seu gênero, para vos servirem de sustento a vós. $\mathrm{E}$ a todos os animais da terra, a todas as aves do céu, e a tudo o que movimento sobre a terra, e em que há alma vivente, para que tenham que comer. E assim se fez", (Gênesis, 1, 27-30). 
outras espécies, tendo o direito delas se servir para alimento, vestuário ou remédio e, paulatinamente, se concebendo como apenas mais um ser vivo, não onipotente, preocupado com o desenvolvimento sustentável e a preservação das outras espécies. É inevitável a referência à obra de Norbert Elias, 0 Processo Civilizador. 0 autor sustenta que: "as pessoas, no curso do processo civilizatório, procuram suprimir em si mesmas todas as características que julgam 'animais'". ${ }^{46}$ Uma destas características é, sem dúvida, 0 ato predatório, não importa qual seja o objetivo.

46 ELIAS, Norbert. O processo civilizador: uma história dos costumes. v.1. Trad. Ruy J ungmann. Rio de J aneiro: J orge Zahar Editor, 1994, p.128. 